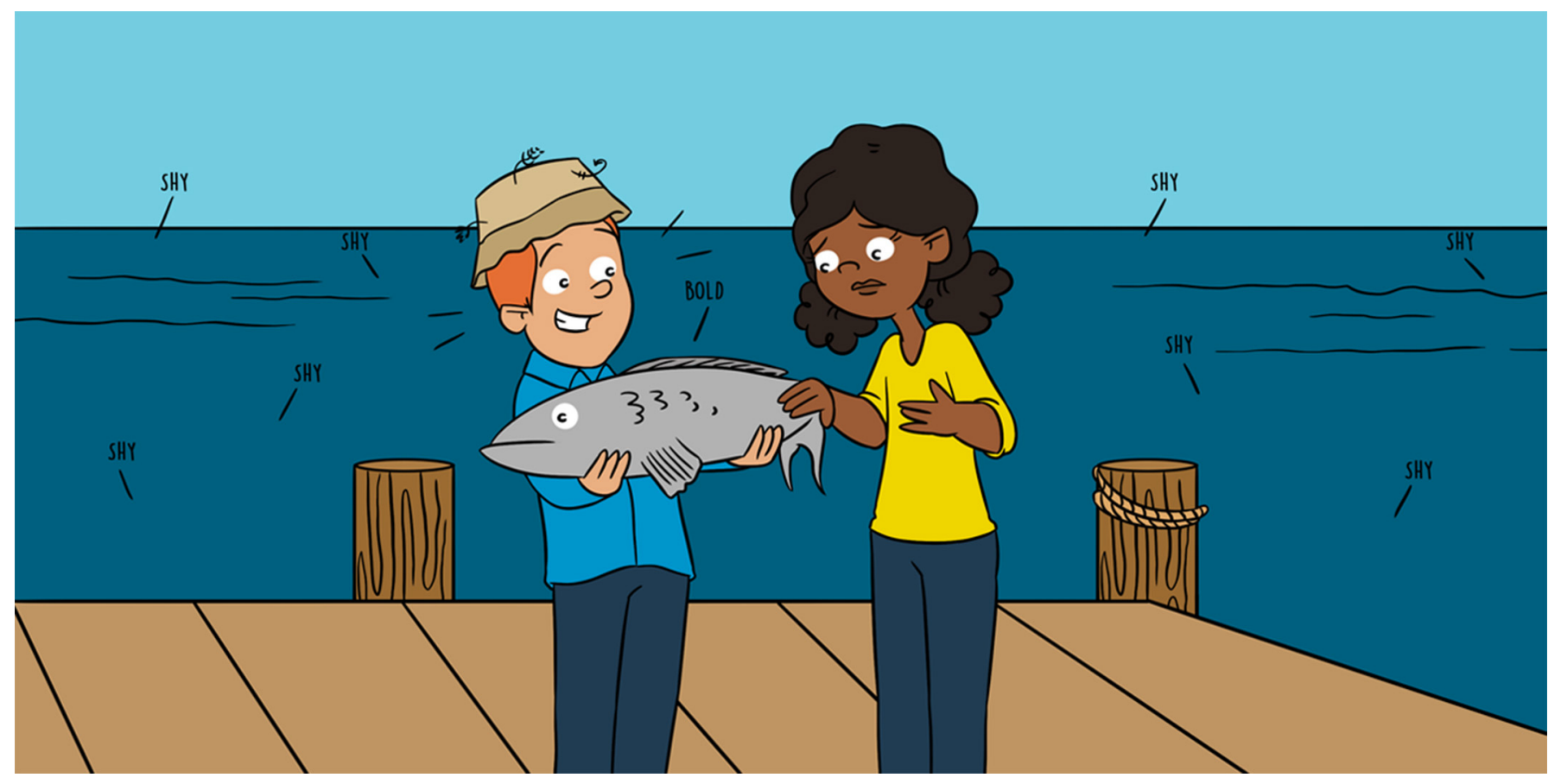

\title{
FISHING CAN TURN BIG FISH INTO SMALL FISH
}

\author{
Beatriz Diaz Pauli ${ }^{1^{*}}$, Vitalija Bartuseviciute ${ }^{1}$ and Mikko Heino ${ }^{1,2,3}$ \\ ${ }^{1}$ Department of Biological Sciences, University of Bergen, Bergen, Norway \\ ${ }^{2}$ Institute of Marine Research, Bergen, Norway \\ ${ }^{3}$ Evolution and Ecology Program, International Institute for Applied Systems Analysis, Laxenburg, Austria
}

YOUNG REVIEWERS:

MEGAN

AGE: 15

POPPY

AGE: 14
People affect animals and plants all over the world. One example is by fishing. Fishing selects fish with unique traits. First, fishers take large fish out of the water. So, populations become small and have only small fish left in them. These fish have babies for the first time when they are younger and smaller. Second, different fishing methods can select fish with different behaviors. So, fishers might catch more timid fish or more active fish, depending on the method. Fishing makes fish populations less diverse and productive. Less diverse means there are only small fish or active fish, not a mix of big, small, active, and timid. Less productive means fewer fish to catch later. Small, less diverse populations are weaker and cannot respond to large changes in the environment. Weaker populations are more difficult to fish in a way that will allow the population to survive. So, fishing makes the fish populations less valuable to the fishers. 


\section{FISHING SELECTS BIG FISH}

When you go fishing, you hope to catch the big fish. Big fish are better to show off to your friends (and enemies). Professional fishers prefer big fish, too. They get paid more for big fish, and it can be illegal to take small fish. Laws specify size limits to protect small fish, so they can grow and reproduce before fishers take them out. Laws protecting small fish help to make sure that fish stay abundant, so there will still be fish to catch in the future.

\section{WHAT IS THE PROBLEM WITH ONLY FISHING BIG FISH?}

Although catching big fish seems to be the best thing to do, there are several problems with this strategy. First, protecting small fish does not guarantee that the fish numbers will remain high. Big fish have more offspring (babies) and their offspring are healthier. So, protecting only small fish can lead to smaller fish populations.

There is a second problem. If we only remove big fish, we will run out of big fish! Offspring size depends on the size of the parents. Big fish will give birth to babies that can grow to become big fish. Small parents will have small offspring. Over time, the number of big fish in the population will be lower.

\section{TRAIT}

Is any characteristic of an organism. For instance, large or small size, bold or shy behavior, early or late maturation.

\section{FISHING-INDUCED} EVOLUTION

The process by which fishing creates changes in the inherited traits of fish, by selection on size, maturation, and/or behavior.

\section{EVOLUTION}

Changes in inherited traits that give organisms a better chance to survive and have offspring.

\section{HERITABLE TRAIT}

A characteristic that is passed from parents to offspring.
Think about a cow farm. Farmers prefer cows with their favorite traits. Big, healthy, well-behaved cows that have many babies and give a lot of milk. Farmers will keep their favorite cows and the best bull to reproduce, to make sure they will have cows with the preferred traits year after year. But we are doing the opposite with the fish in the sea! If we want the best fish, we should do what farmers do. We should leave the big fish in the sea, so they reproduce. That way, we will always have big fish.

\section{FISHING TRIGGERS EVOLUTION}

Fishing-induced evolution is a term used by scientists to describe the fact that fishing changes the fish. Fishing affects fish in oceans, seas, lakes, and rivers. Evolution is the change in traits, or characteristics like size, color, or certain behavior patterns, that are passed on from parents to offspring. Evolution happens when two things occur at the same time. First, a trait (for example, size) gives the fish a better chance to survive and have babies. Second, the trait is an heritable trait, which means it can be passed on from parents to their offspring. Fishing can trigger evolution. First, fishing removes the big fish. So, the small fish will have a better chance to survive and reproduce. Second, size is heritable. It passes from parents to offspring through their genes. So, when fishers continually remove the big fish, the smaller fish 


\section{MATURATION}

The stage of development that makes an organism able to reproduce for the first time. reproduce and eventually, through evolution, the entire population will consist of smaller fish.

\section{FISHING SELECTS FOR MORE THAN JUST SIZE!}

Fishing does not only select for fish of a certain size. Fishing can select on other characteristics too [1], for example, maturation and behavior. Keep reading to see how this happens!

\section{Maturation}

Maturation is an important time in the life of any species. It is the time when the fish change from juveniles to adults and become able to reproduce and produce offspring for the first time. A lot of energy is needed to mature, and the sources of this energy are scarce. So, during the maturation period, a fish needs to grow slower or even stop growing to channel energy to the maturation process. The energetic cost to the fish can even decrease the chances of its survival.

The age and size at which a fish is ready to mature depend on two things: the amount of food the fish can obtain from the environment and how the fish shares the food among its important life processes. These life processes include growing, maturing, storing energy, and surviving. These life processes compete for the energy provided by food. The amount of food and the way food is shared between life processes depends on many things, including the temperature of the water, how many predators exist, how much food there is, and how many fish are living together.

In general, fish can use one of two life strategies that affect the age at which they mature and the other life processes:

- "Live fast, die young" strategy. If the risk of death is high, it is not worth trying to reach old age and energy should be put toward reproduction. For example, when fishers are fishing loads of fish, the amount of fish death is high. In that case, the best strategy is for a fish to put all its energy into maturing quickly and reproducing early, to have offspring before fishers catch them.

- "Live slow and grow old" strategy. If the risk of death is low, fish can have a long future waiting for them, and there is no rush to mature or reproduce. The best strategy is to mature and reproduce later in life. These fish can grow larger and have more offspring. Larger fish can live longer, because big fish have fewer natural enemies than small ones.

Fishing favors the "live fast, die young" strategy [1]. Fish mature younger and smaller in fished populations. So, fishing affects maturation in two ways. First, fishing leads to more death, so fish must live fast. Second, 
Figure 1

Examples of

fish species that exhibit the "live fast, die young" strategy. Fishing has caused these fish to mature at an earlier age and become smaller in size [1]. The colored markers show where each species lives. Fish images (c) Sockeye salmon and chum salmon: Timothy Knepp, U.S. Fish and Wildlife Service [Public domain]. American plaice and sole: Jonathan Couch, 1877 [2]. Lake whitefish: Ellen Edmonson and Hugh Chrisp, 1927-1940

[Public domain]. Atlantic herring: Gervais et Boulart, 1877 [Public domain]. Haddock: University of Washington [Public domain]. Estuary cobbler: Bernard Yao, reproduced with permission. Cod, European plaice, and Norway pout: Institute for Marine Research, Norway (Øystein Paulsen, Eivind Senneset, and Mareano, respectively). Whiting and Pikeperch: Krüger 1795 and 1797 [Public domain].

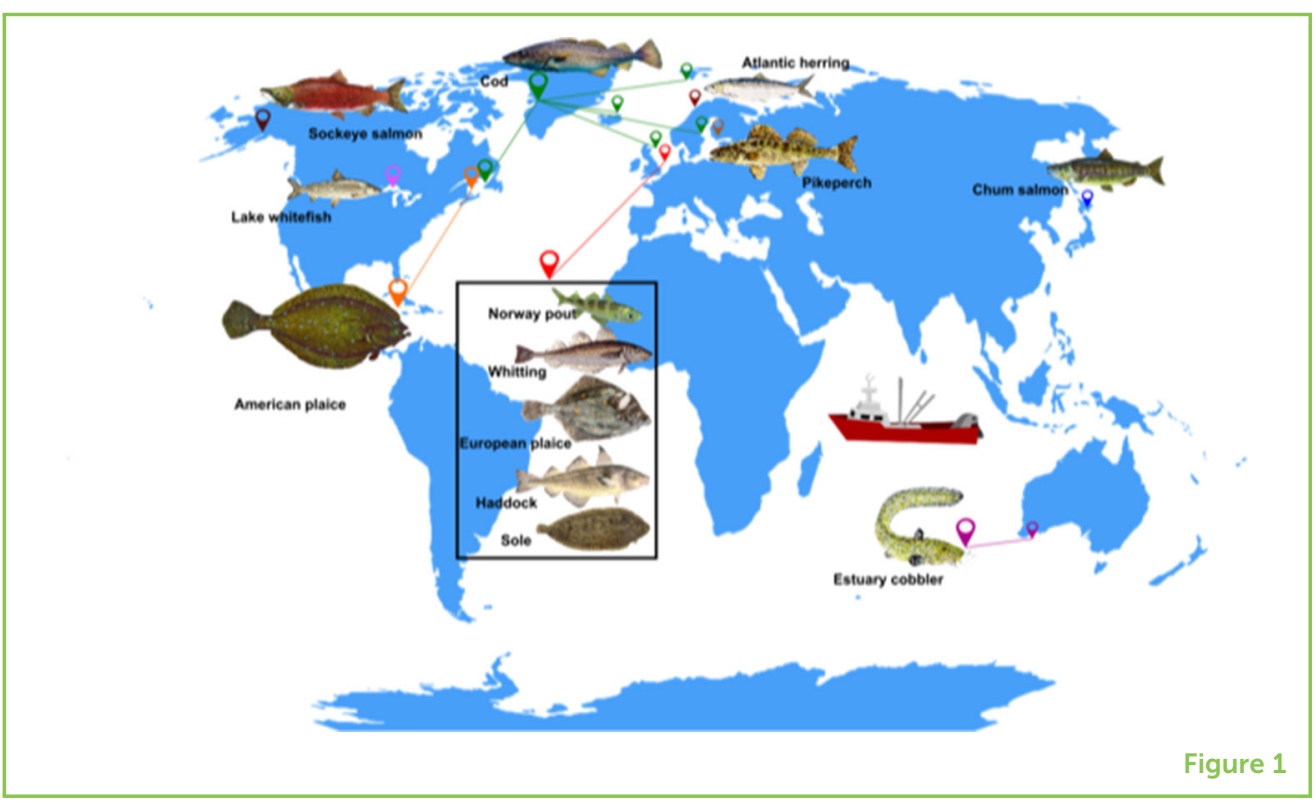

fishing removes large fish, so the small fish that mature young have more offspring than the bigger fish that mature late.

\section{Behavior}

Only a few scientists study the combination of fish behavior, fishing, and evolution. It is a new idea. However, many researchers have observed that fish in today's waters mature younger and smaller (Figure 1). Maturation is the first fish trait that we and other researchers studied, because data on fish size and maturation are easy to collect. We also study how fish behavior is related to fishing [3, 4]. We do our experiments in the lab if we cannot do them directly in the sea. We think that we can witness the evolution of fish during our lifetime. This is awesome but also a bit scary!

There are two types of fishing, passive and active (Figure 2). Passive fishing is when fishers wait for the fish to come. They use traps, nets called gill nets, or fishing rods. Active fishing is when the net moves to capture fish. These nets are called trawl or seine nets. Scientists and fishers know that the behavior of the fish determines which fishing technique they should use. If fish gather in schools, then fishers can use a fishing trawl, but if fish are more solitary and have a huge appetite, then fishers can use a fishing rod with a juicy bait.

Fishing rods catch fish that are bold and like taking risks. In these bold populations, the shy fish survive longer, so they have more baby fish than the bold fish do. In this way, rod fishing helps populations of shy fish to develop, because they do not like taking risks [4]. We have less information about active fishing and fish behavior. Scientists use cameras in the sea to study fish behavior. Previous studies found that active fishing catches fish that all swim at the same speed. Fish that change speeds, alternating between swimming fast and slow, are 
Figure 2

Although fish in wild natural populations might seem to all be the same, the individual fish actually have a surprising level of diversity in traits, including size and behavior. You can see size differences in the figure, and the different colors show bold and shy fish. Fishing can affect the natural diversity in the fish population by selecting on large fish, or fish that are either shy (pale blue) or active and bold (dark blue). Too much fishing leaves only the smaller,

harder-to-catch fish in the population and when those fish reproduce, these physical and behavioral traits may be passed on to their offspring.

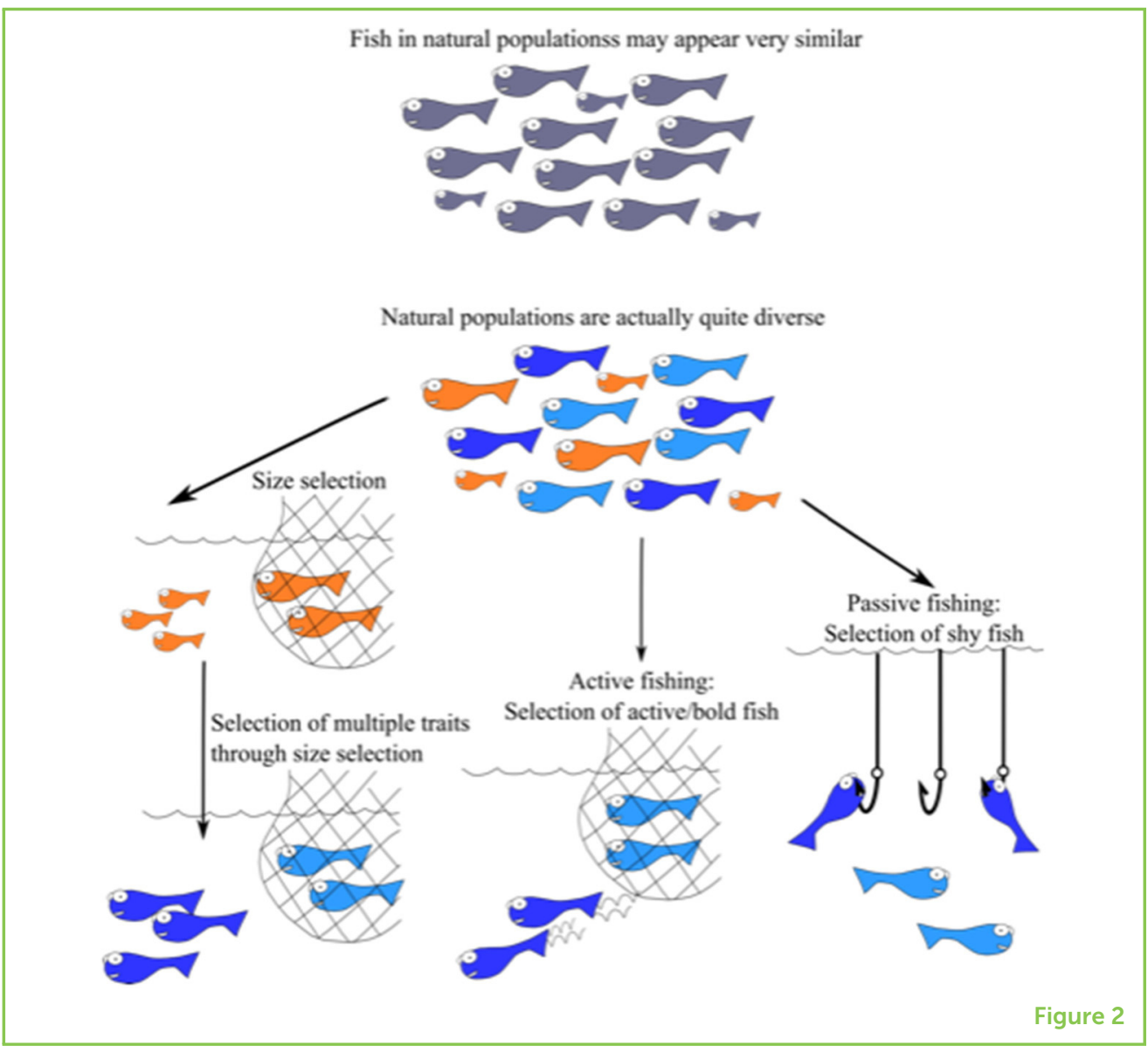

more likely to escape the net. These fish survive longer and reproduce more. We and other scientists saw similar results in experiments we did in the lab. We used small trawl nets inside an aquarium and saw that bold fish escaped the nets by being more active and better at swimming [3].

\section{Multiple Characteristics at the Same Time}

As we explained, fish have many traits linked to their living processes. These traits depend on each other and on the amount of energy the fish has. A fish with a "live fast, die young" strategy matures early and has more offspring. But to do so, the fish must grow slower and invest less energy into its defense strategies. This "live fast" fish will be bolder and eat more [5]. So, fishing not only leads to smaller-sized fish. It should also drive changes in many other traits. We are only starting to learn about how fishing affects the evolution of all these new traits. Our plan is to study more traits to see how they are affected by fishing. We will first do our experiments in the lab, because it is easier than in the sea. We want to see how "live fast" fish defend themselves from predators and diseases. We also want to study how much they eat and how they affect the food web. This information will help us to understand the effects of fishing on the whole ecosystem. 


\section{SUSTAINABLE ACTIVITY}

It uses the resources of the planet in a way that maintains them at levels similar to the present levels, so the resources will be conserved for the future generations.

\section{CAN WE MAKE FISHING LESS DAMAGING TO FISH POPULATIONS?}

Fishing causes changes in the fished populations. Fishing not only kills fish, but it also tends to leave the remaining fish populations less abundant (fewer fish) and less diverse (fewer different traits). If fishing causes fish to evolve into smaller, less diverse populations, then future generations of fish might be in trouble. We know that small and less diverse populations are weaker because the fish may not be able to deal as well with changes in the environment and may eventually die out. The remaining fish in the evolved population are also less valuable for fishers and are more difficult to catch, which makes fishing less profitable. When an activity has such negative effects on a population of organisms that the population may not recover, we say that the activity is not a sustainable activity. Many of our current fishing methods are not sustainable and may permanently damage fish populations. To save the fish, and to make fishing more sustainable, we need to fish less. We can also reduce the fishing selection, for instance by also actively fishing for medium-sized fish, instead of only taking out the big ones. We can also combine different fishing methods that target different traits to maintain diverse populations. In general, our fishing practices should be adapted to maintain fish with the preferred traits in the sea just like cow farmers keep their favorite cows. But mostly, our fishing practices should protect diversity in the fished populations. Large and diverse fish populations are more sustainable.

\section{ACKNOWLEDGMENTS}

We would like to thank the two young reviewers for reading through our manuscript, their interest and very useful comments. We were grateful to the editor Pedro Morais for his suggestions to improve readability. We also thank the Research Council of Norway (project number 275125) for funding our work.

\section{REFERENCES}

1. Heino, M., Diaz Pauli, B., and Dieckmann, U. 2015. Fisheries-induced evolution. Annu. Rev. Ecol. Evol. and Syst. 46:461-80. doi: 10.1146/annurev-ecolsys-112 414-054339

2. Aflalo, F. G. 1904. Freshwater and Marine Image Bank. Seattle, WA: University of Washington.

3. Diaz Pauli, B., and Sih, A. 2017. Behavioural responses to human-induced change: why fishing should not be ignored. Evol. Appl. 10:231-40. doi: 10.11 11/eva.12456

4. Arlinghaus, R., Laskowski, K. L., Alós, J., Klefoth, T., Monk, C. T., Nakayama, S., et al. 2016. Passive gear-induced timidity syndrome in wild fish populations and 
its potential ecological and managerial implications. Fish Fish. 18:360-73. doi: $10.1111 /$ faf.12176

5. Réale, D., Garant, D., Humphries, M. M., Bergeron, P., Careau, V., and Montiglio, P. O. 2010. Personality and the emergence of the pace-of-life syndrome concept at the population level. Philos. Trans. R. Soc. B Biol. Sci. 365:4051-63. doi: $10.1098 /$ rstb.2010.0208

SUBMITTED: 17 February 2020; ACCEPTED: 23 July 2020; PUBLISHED ONLINE: 26 August 2020.

EDITED BY: Pedro Morais, University of Algarve, Portugal

CITATION: Diaz Pauli B, Bartuseviciute V and Heino M (2020) Fishing Can Turn Big Fish Into Small Fish. Front. Young Minds 8:112. doi: 10.3389/frym.2020.00112

CONFLICT OF INTEREST: The authors declare that the research was conducted in the absence of any commercial or financial relationships that could be construed as a potential conflict of interest.

COPYRIGHT @ 2020 Diaz Pauli, Bartuseviciute and Heino. This is an open-access article distributed under the terms of the Creative Commons Attribution License (CC BY). The use, distribution or reproduction in other forums is permitted, provided the original author(s) and the copyright owner(s) are credited and that the original publication in this journal is cited, in accordance with accepted academic practice. No use, distribution or reproduction is permitted which does not comply with these terms.

\section{YOUNG REVIEWERS}

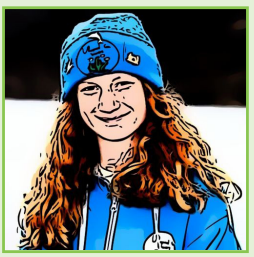

\section{MEGAN, AGE: 15}

$\mathrm{Hi}$, I am Megan and my passion is the sea. It is lucky for me that I live on the west coast of Scotland and can spend most of my time kayaking, swimming, and sailing. My love of the outdoors has driven a fascination with science (which was how I ended up reviewing this paper), and I want to be a marine biologist when I am older.

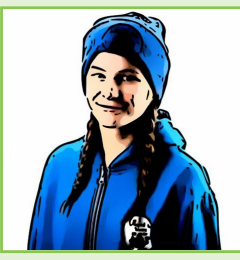

\section{POPPY, AGE: 14}

Poppy lives in the Nort West Highlands near Ullapool and is 14 years old. She is a founder member of Ullapool Sea Savers and has been involved in many high profile campaigns to help protect the seas and our environment. In her free time Poppy enjoys sports and taking her 2 dogs on adventures.

\section{AUTHORS}

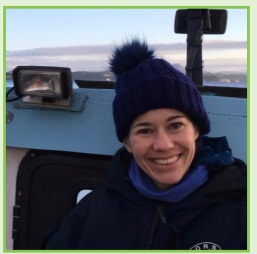

\section{BEATRIZ DIAZ PAULI}

I am interested in how human activities are affecting the life and behavior of wild populations. I have mainly worked with fish, studying how they are affected by different human activities especially fishing. I graduated in Biology from the University of Murcia, Spain (2005), then worked at the University of Helsinki, Finland, 


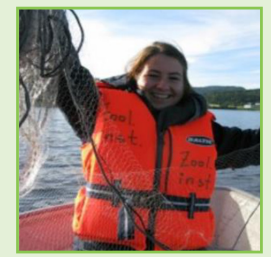

\section{VITALIJA BARTUSEVICIUTE}

I am interested in life-history strategies and the trade-offs of improvement in one trait vs. another. I mainly work in the laboratory and I started by measuring the effects of climate change in plants at Vytautas Magnus University (2016), where I completed my Bachelor's degree. Later, I worked with the waterflea Daphnia magna at the Norwegian University of Science and Technology, where I completed my Master's degree (2018). Now I am a Ph.D. student at the University of Bergen. Here, I want to understand how guppies respond to fisheries-induced evolution.

\section{MIKKO HEINO}

I am an evolutionary ecologist interested in how organisms adapt to their environments, especially when they are faced with new challenges, such as fishing. I often use mathematical models to understand these questions, but also experiments and field data. I typically work with fish, not only because of their ecological and economic importance, but also because there are plenty of data available. I have my M.Sc. and Ph.D. degrees from the University of Helsinki, Finland. Since 2007, my main employment has been at the University of Bergen, Norway. 